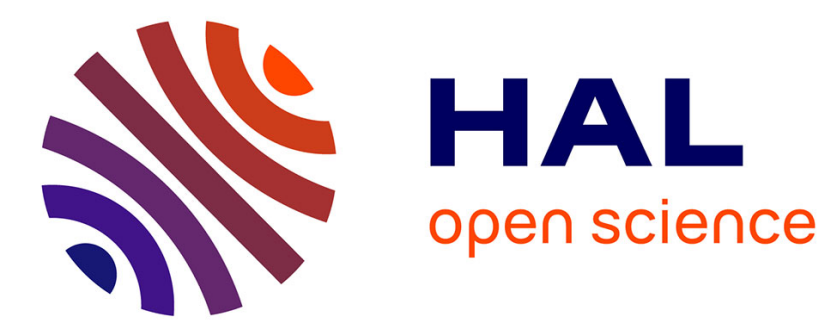

\title{
Sensitive detection of laser-ablation plumes in an optical build-up cavity
}

E. Benck, H. Schuessler

\section{To cite this version:}

E. Benck, H. Schuessler. Sensitive detection of laser-ablation plumes in an optical build-up cavity. Journal de Physique IV Proceedings, 1994, 04 (C7), pp.C7-741-C7-743. 10.1051/jp4:19947174 . jpa00253235

\section{HAL Id: jpa-00253235 https://hal.science/jpa-00253235}

Submitted on 1 Jan 1994

HAL is a multi-disciplinary open access archive for the deposit and dissemination of scientific research documents, whether they are published or not. The documents may come from teaching and research institutions in France or abroad, or from public or private research centers.
L'archive ouverte pluridisciplinaire HAL, est destinée au dépôt et à la diffusion de documents scientifiques de niveau recherche, publiés ou non, émanant des établissements d'enseignement et de recherche français ou étrangers, des laboratoires publics ou privés. 


\title{
Sensitive detection of laser-ablation plumes in an optical build-up cavity
}

\author{
E.C. Benck and H.A. Schuessler \\ Department of Physics, Texas A\&M University, College Station, TX 77843-4242, U.S.A.
}

\begin{abstract}
Cavity-enhanced detection is used to monitor the dynamics of minute vapor plumes produced by focusing a pulsed laser beam onto a surface. The time evolution of the various processes, namely vaporization, acoustic wave generation and photothermal effect range from nsec to msec.
\end{abstract}

\section{INTRODUCTION}

Cavity-enhanced detection has been used as a sensitive probe of laser-ablation plumes. The tiny plume ejected from a solid or liquid surface by a focused pulsed laser beam is monitored inside an optical cavity by a fixed frequency $c w$ probe laser beam. The weak absorption, scattering and optical pathlength changes occurring in the plume are amplified by the quality factor of the high-finesse optical cavity, since the probe beam is resonant with the optical cavity.

\section{EXPERIMENTAL APPARATUS}

Vaporization of surface materials is produced by a single transverse mode tunable pulsed dye laser which is focused to a $20 \mu \mathrm{m}$ diameter spot on a sample located inside a confocal etalon. This pulsed dye laser is called the pump laser and produces pulse energies in the range of 0.35 to $35 \mu \mathrm{J}$ at $\lambda=640 \mathrm{~nm}$ with a pulse length of $10 \mathrm{~ns}$. The dynamics of the laser plume above the pump beam focal spot are monitored by the probe HeNe laser. The mode-matched HeNe beam is split into two sub-beams which both are injected into the elalon. One sub-beam is used to probe the laser plume and grazes the sample surface above the focal spot of the pump laser beam. This beam contains the signal as a change in phase and amplitude. The other sub-beam is used to stabilize the etalon by locking it to the side of a transmission fringe and, thereby, to the HeNe-laser frequency. Between each pulse of the pump laser the sample is advanced by a precision translation stage so that each time a virgin portion of the surface is exposed. The signals are recorded with a fast digital storage oscilloscope and the data are transferred to a personal computer for averaging. 


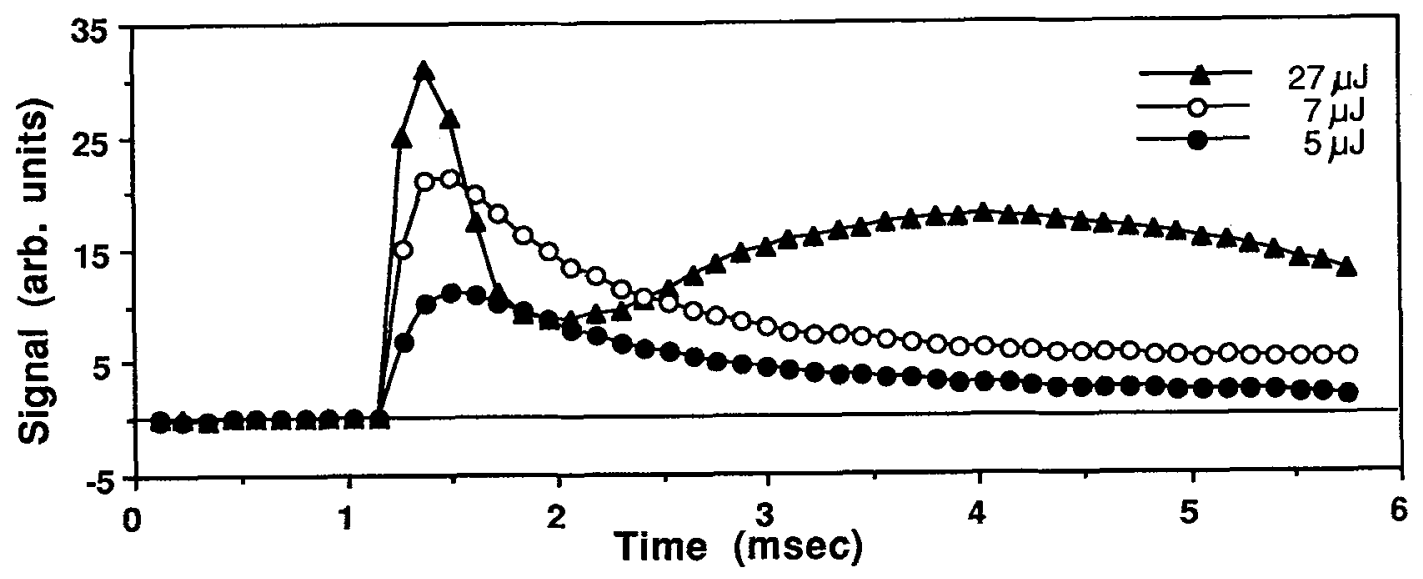

Fig. 1. Cavity-Enhanced signals from an ablation plume of lead versus time for several different laser intensities.

\section{RESULTS}

Three types of cavity-enhanced signals were observed and occur on different time scales.

On a nsec time scale the cavity-enhanced signal is produced by the direct interaction of the ablated material with the probe beam. The velocity of the ablated material can reach supersonic speeds.[1] Due to the small signal and the large amount of electrical noise produced by the pump laser, it is necessary to average the signals from approximately 50 laser pulses to produce a clear signal. The major contribution to the signal is due to a change in the index of refraction produced by the ablated material and results in a phase change of the transmitted beam. However the cavity-enhanced signal is also effected by the absorption and scattering of the probe beam, which leads to a decrease of the amplitude of the probe beam.

In addition the supersonic ablation of the material produces an acoustic shock wave, which a few mm away from the surface occurs on a $\mu \mathrm{sec}$ time scale. The compression and rarefaction of the air by the shock wave results in a cavity-enhanced signal with both a positive and negative polarity.

Finally on a much longer msec time scale, a hot air plume rises above the sample. The amplitude and temporal structures of these thermal signals were previously reported[2,3]. The cavity-enhanced signal consists of a single peak when the maximum pump laser energy of 35 $\mu \mathrm{J}$ is focused onto materials with melting points above $400^{\circ} \mathrm{C}$. This signal is caused by the reduced index of refraction within the convective plume of heated air. Lower melting point materials produce a signal with a double peaked structure. By reducing the pump laser intensity, a single peak signal can also be obtained from the low melting point materials. The double peaked signals are interpreted as being caused by chaotic turbulence or boiling of the material on the surface.

Examining the surfaces with a microscope showed surface damage in all samples. The width of the damage spots produced on low melting point targets, such as lead $\left(\mathrm{T}_{\mathrm{m}}=328^{\circ} \mathrm{C}\right)$, is three times as large as the focal spot of the laser. In the other extreme, the cratering produced in refractory metals, such as tungsten $\left(\mathrm{T}_{\mathrm{m}}=3410^{\circ} \mathrm{C}\right)$, was much smaller than the focal spot and had a diameter of only a few $\mu \mathrm{m}$. The production of solidified droplets was observed on most of the metal surfaces studied. 


\section{References}

[1] J. A. Sell, D. M. Heffelfinger, P. L. G. Ventzek, and R. M. Gilgenbach, J. Appl. Phys. 69 (1991) 1330.

[2] E. C. Benck, Z. Rong, S. H. Chen, Z. C. Tang, and H. A. Schuessler, Appl. Phys. Lett. 58 (1991) 1476.

[3] E. C. Benck, Z. Rong, S. H. Chen, and H. A. Schuessler, Appl. Surface Science 48 (1991) 257. 